\title{
Statin-use debate creates furor at The BMJ
}

\section{${ }^{66} \mathrm{~A}$} re statins going to have a big impact on coronary artery disease or are they going to be one of the big mistakes that the medical profession has made?" That's the question asked by Dr. James Wright, a Canadian who coauthored an analysis of the evidence on statins in The British Medical Journal (The BMJ) in October 2013.

It seems like a straightforward question, but that article has led to a furor in the United Kingdom, with a wellknown researcher calling for its retraction and The BMJ Editor-in-Chief Fiona Godlee defending the journal's publishing process on radio and television. At issue is the clinical uncertainty about the preventive use of statins.

"We're fairly certain that benefits outweigh the harms in people with proven coronary artery disease (CAD). That's based on a highly statistically significant but modest reduction in total mortality," says Wright, who is managing director and chair of the Therapeutics Initiative (TI) at the University of British Columbia in Vancouver. But he says most prescriptions for statins are aimed at preventing CAD. The evidence for this is not as rigorous, and serious adverse effects have been documented.

The UK's National Institute for Health and Care Excellence (NICE) recently proposed extending preventive use of statins from patients who have a $20 \%$ risk of CAD in the next 10 years (its current guideline) to those with a $10 \%$ risk. This has led to a debate over the accuracy of risk calculators, unnecessary prescribing in seniors (because age is a major risk factor) and adverse effects. Canada's guidelines recommend statin therapy in patients with risk below $20 \%$ only if their levels of cholesterol or other indicators exceed certain thresholds.

Wright believes the statin issue has become heated because "so many people are taking them. They have been in the news so much, and there [is] so much money being spent on them.'

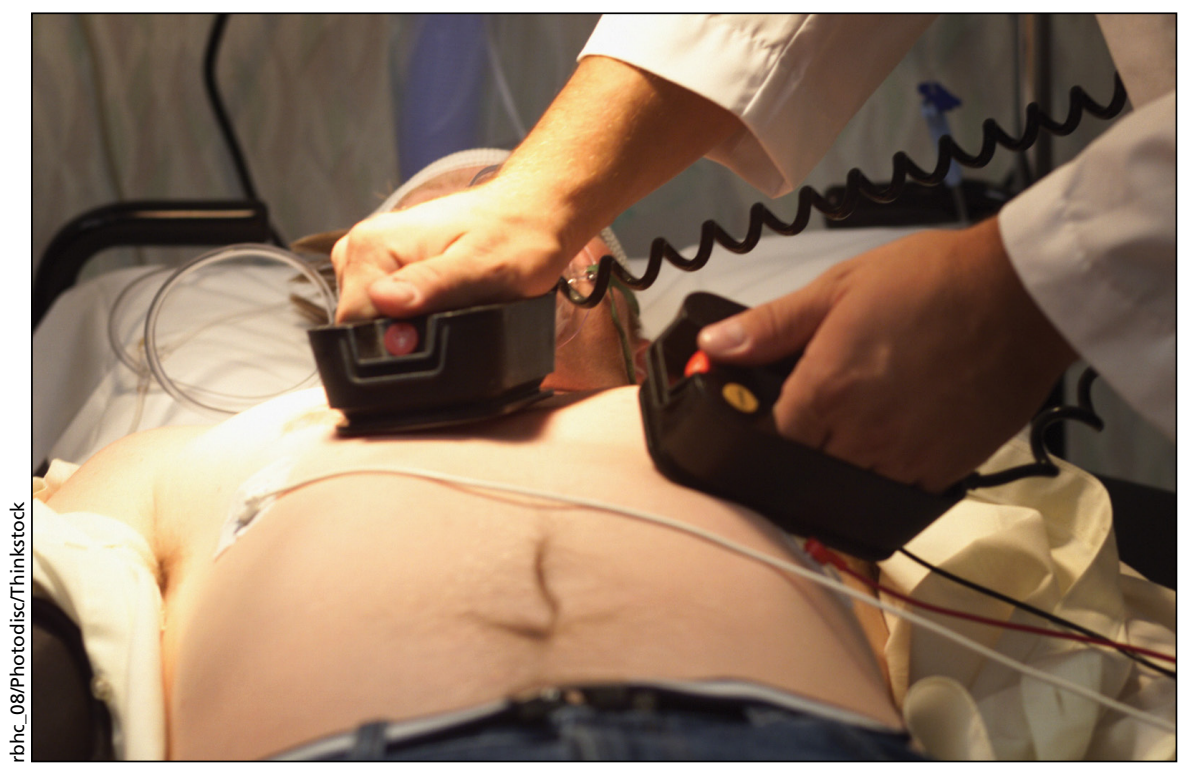

Statins are beneficial for people with proven coronary artery disease, but a recent article in The $B M J$ questioned their use as a prophylactic measure.

"Publication of our article has reignited the debate," says Dr. Kamran Abbasi, international editor of The $B M J$, who spoke on behalf of Godlee. "There are people who disagree vehemently on this issue. They can't reach any sort of consensus on it at the moment."

The $B M J$ article reanalyzed data from the Cholesterol Treatment Trialists' (CTT) Collaboration meta-analysis and cited adverse effects rates from various studies. Sir Rory Collins, a researcher at Oxford University and head of the CTT group, corresponded directly and met with Godlee in December 2013 about the article, calling for a retraction. He has also stated his view in media interviews.

As a result of Collins' complaint, the article was corrected, because the authors agreed that they had erred in reporting rates of side effects from the observational study. Wright says, "the issue around side effects is just that there is some harm." The analysis had cited a rate of statin-related adverse effects of $18 \%$; in fact, the original study found $17.4 \%$ of patients had a "statin-related event" but only approximately $9 \%$ discontinued statin therapy as a result. The correction affirmed that the CTT study failed to show that statins reduced the overall mortality risk in patients with a less than $20 \%$ risk of CAD over 10 years.

Godlee also published an editorial explaining the journal's decisions on how to handle the controversy and appointed an independent panel to rule on whether a retraction is warranted. Collins says he has submitted detailed material to this panel and maintains that there remain "extensive problems" with the analysis paper, beyond what the correction addressed.

Charlotte Haug, vice-chair of the Committee on Publication Ethics (COPE), an international organization devoted to ethical issues in scientific publishing, says they are seeing more cases in which articles are retracted instead of being corrected or discussed. She says the attitude is, "if I disagree with you, I think this should be retracted," and in a recent editorial, Haug called this "bully-boy tactics." COPE guidelines state that retraction "should usually be reserved for publications that are so seriously flawed that their findings or conclusions should not be relied 
upon," whether because of misconduct or honest error. The guidelines also say that if a small part of an article is in error, a correction is appropriate.

Abbasi says The BMJ welcomes criticism. "We don't mind people saying we should be retracting this. We're part of the scientific community, and we want people to say when we've got it wrong. But we may not agree with them."

Abbasi also downplays concerns that pharmaceutical industry pressure may have influenced this issue. Dr.
Peter Gøtzsche, a founder of the Cochrane Collaboration and author of a book that is critical of pharmaceutical industry involvement, said in a rapid response on The BMJ website, "Industry-funded randomized trials are notoriously unreliable when it comes to the harms of drugs." He elaborated in an email: "Collins and colleagues have huge conflicts of interest in relation to their work."

Collins counters that the meta-analysis was funded by government and charity grants. And while the majority of studies analyzed were industryfunded, some were not.

Abbasi believes physicians on both sides of the statin debate are motivated to help patients. "When researchers study a particular drug or treatment, they become wedded to that idea. They are not necessarily dancing to the tune of the pharmaceutical industry." Carolyn Brown, Ottawa, Ont.

CMAJ 2014. DOI:10.1503/cmaj.109-4825 